\title{
Toward a General Theory of Wage and Price Rigidities and Economic Fluctuations
}

\author{
By JoSEPH E. STIGLITZ*
}

This paper begins with the hypothesis that large economic fluctuations, the marked changes in the unemployment that characterize market economies, are a consequence of problems of adjustment to disturbances, especially adjustments of wages and prices. Two strands of work have addressed these problems of adjustment. One focuses on rigidities: downward rigidities in wages are at the center of traditional Keynesian models. The other focuses on the consequences of rapid changes, particularly in asset prices, in the context of markets with incomplete contracting (imperfect indexing) and imperfect capital markets. While the second tradition traces its origins at least back to Irving Fisher's debt-deflation theories, it has been revived in the newKeynesian work of Bruce Greenwald and Stiglitz (1988, 1989, 1990b, 1993, 1995) and others. The fact that wages and prices did fall dramatically in the Great Depression (by more than a third in the United States) provided some of the impetus to the latter theory. The major economic downturn this year in East Asia, with unemployment in Indonesia soaring from 4.7 percent to 14.3 percent and output falling by at least 16 percent, was accompanied by huge changes in prices: over the first year of the crisis, the current best estimate is that Indonesian real wages fell by $40-60$ percent (World Bank, 1998 p. 105). This result, I would argue, is better interpreted through the second strand of thought.

\section{Asymmetries in Adjustment Speeds}

This paper carries the analysis one step further. It argues that, because different prices

\footnotetext{
* World Bank, Washington, DC 20433; on leave from Stanford University. The views expressed are solely those of the author and do not necessarily represent those of any organization with which he is or has been affiliated. This paper is based on joint research with Bruce Greenwald.
}

(including prices of labor and capital) are determined in different ways, shocks lead to marked changes in relative prices, and those disturbances in relative prices greatly exacerbate economic fluctuations. The determination of asset prices is often best described by the auction markets emphasized in traditional economics texts. These prices adjust quickly; and because the value of assets today depends on expectations of future values, current prices can be highly volatile, as those expectations change. On the other hand, prices of most products, wages, and bank interest rates are set by firms (and banks), albeit in the context of markets. Firms face downward-sloping demand curves for their products in the short run and upward-sloping supply curves for factors. These slopes can be explained in part by imperfections in competition due to product differentiation or to the small number of firms in the market and in part by information imperfections.

The importance of downward-sloping product demand (at least in the short run) has been brought home forcefully by the recent crisis in East Asia. Consider the example of Thailand, which, with less than 1 percent of world GDP, is a small player in the world economy. Under standard theory, it would face a horizontal demand curve for its products; certainly a 30percent real devaluation should lead to huge increases in the demand for its products. Exports would quickly fill up any loss in domestic demand. Yet in fact, the value of Thai exports actually declined in the aftermath of the crisis (Greenwald, 1998).

For price- and wage-setting firms, the consequences of changes in prices and wages are uncertain, not only because prices and wages have to be set before demand and supply curves are fully known, but also because the reactions of other agents in the market are uncertain. The uncertainty arises for two reasons: first, because changes in a firm's 


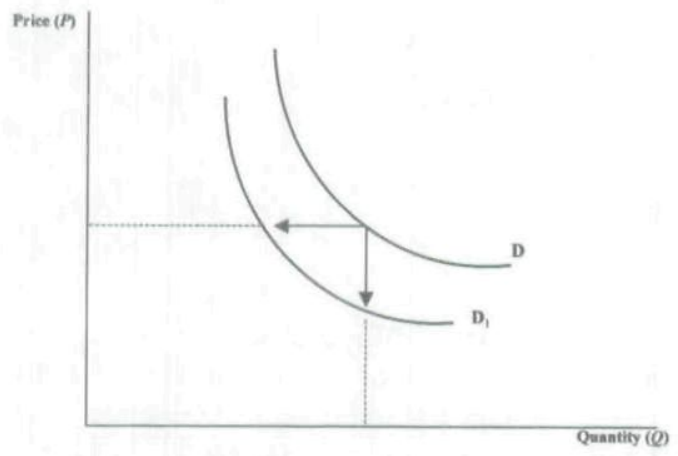

Figure 1. Price versus Quantity AdJustment

Notes: If there is a shift in the demand curve, either price or quantities must change. The smaller the adjustment of prices, the larger is the adjustment of quantities. With uncertainty in the demand curve, different adjustments in prices impose different risks on the firm.

circumstances (including the signals they receive) are only imperfectly known by other firms; and second, because firms receiving the same information or the same shocks will react differently, depending on their circumstances and characteristics (which are not common knowledge). Both because of agency problems and imperfections of capital markets, which lead to firms acting in a risk-averse manner (Greenwald and Stiglitz, 1990a), firms are sensitive to the risks associated with different decisions. The problem of price- and wage-setting thus should be approached within a standard dynamic portfolio model, one that takes into account the risks associated with each decision, the nonreversibilities, as well as the adjustment costs associated with both prices and quantities (see Fig. 1). My earlier papers (with Greenwald) have argued that (a) the risks associated with wage and price adjustments may well be larger than those associated with output adjustments, at least for goods that could be stored; and (b) there were fixed costs associated with hiring and firing, and those costs were often asymmetric. These asymmetries helped explain the pattern of hours and employment over the cycle, with increases in hours (entailing high overtime payments) typically preceding increases in employment, and with labor-shedding typi- cally lagging downturns (giving rise to the phenomenon described as labor-hoarding).

In the following sections, I look more closely at the price-setting process, providing further insights into why prices exhibit rigidities and why different prices may adjust at different rates. I then explore the consequences of asymmetric price responses.

\section{Signaling and Rigidities}

Earlier analyses explained why the level of wages or prices might affect the quality of the labor hired or of the good purchased. These effects have profound implications for the shape of the demand and supply curves, and they imply that wages and prices may not adjust to market-clearing levels. Here, however, the concern is with how economies respond to shocks. Efficiency-wage theories, for instance, argue that, while real wages may not adjust to a change in the supply of labor, they will typically change in response to other changes in economic circumstances, including information (e.g., about the productivity of workers). In a dynamic economy, changes in prices and wages may convey information, about both the characteristics of a firm and changes in those characteristics. For instance, if a firm responds quickly to the lowering of prices by a competitor, this action may convey information about the firm's willingness to meet or its ability to withstand competition. By the same token, given asymmetries of information about a firm's balance sheet, large changes in prices may convey information of particular importance to a firm's creditors (e.g., that the firm needs to liquefy assets quickly). (Firms facing the threat of bankruptcy are often forced to engage in quick inventory reductions; the fact that the signal is costly makes it a very effective signal.) It is the change in observable behavior that conveys information.

The information conveyed by changes in prices is all the greater when there are costs to changing prices, as in the menu-cost literature. In this case, the change conveys information that the shock to the environment (e.g., to the net worth of the firm) is greater than some critical threshold level.

Signaling theories thus suggest that, to the extent that it is changes in behavior that con- 


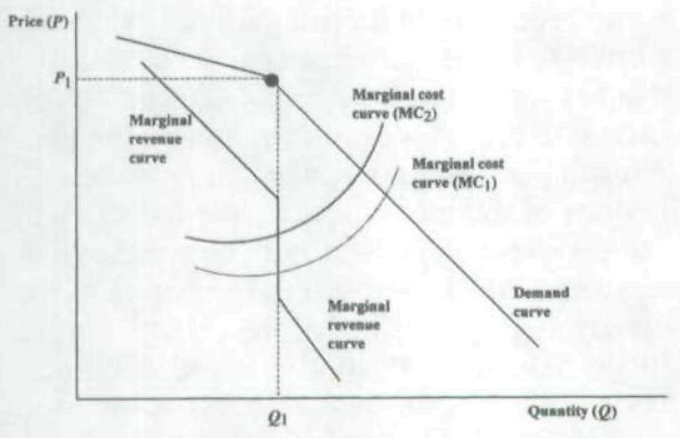

Figure 2. Kinked Demand Curves

Notes: Conventional search models give rise to firms facing kinked demand curves. The gains to lowering prices may be markedly lower than the losses from raising prices.

vey relevant information, there will be strong rigidities in variables that are publicly observable. While inventories and much of the internal workings of firms are not observable, by their very nature, prices have to be at least partially observable to outsiders (to those engaging in the trade). Similarly, layoffs may convey a strong signal, especially to other workers at the firm, that may induce those not laid off to commence searching for alternative employment. The recognition that various actions can convey information may provide an incentive for secrecy and for firms to take actions to otherwise obfuscate signals and their interpretations. Like other attempts to block information flows, this practice may interfere with overall economic efficiency (see Aaron S. Edlin and Stiglitz, 1995).

Much of the signal is related to deviations from norms. That is, if all firms are increasing prices by 3 percent, or if the firm has always increased its price in line with the rate of inflation, then deviations from either norm will convey information about the changed circumstances of the firm. Since norms can differ in different countries and can change dramatically, it may be difficult to relate price-setting processes just to fundamentals.

The state of the economy may affect the information conveyed by a particular action, causing more rigidities in some circumstances than others. Thus, if the state of the economy is such that bankruptcy is a real danger, a firm may have a strong incentive to avoid signaling that it faces a higher probability of bankruptcy; as a result, prices may be relatively rigid in this situation. On the other hand, if the state of the economy is such that most firms are markedly decreasing prices, then the signal conveyed by a price decrease by a firm may be weaker, and it could simply be interpreted as reflecting lower costs of production or an effective response to competitive pressures.

Firms may, of course, be uncertain about the full implications of signals conveyed by wage and price changes, including how competitor firms, customers, or suppliers (including creditors) will respond to those changes. This risk, combined with firm risk aversion, reinforces the reluctance to change prices.

\section{Search and Rigidities}

Search is costly, and the extent of search depends on perceptions of whether the offered price (wage, interest rate) deviates from that being offered by others. Elsewhere (Stiglitz, 1987), I have shown that this can give rise to a kinked demand curve in product markets. The reasoning is as follows: When a firm raises its price (by more than the "norm"), the firm's customers immediately know it and are induced to search for alternative suppliers. But if it lowers its price, then unless it expends resources on advertising, its action induces no new customers to launch a search; and while it will glean more customers (as those currently searching are more likely to settle on this firm), the increased sales under plausible conditions will be markedly less than the loss in sales from price increases (see Fig. 2). Similar arguments hold in other markets. The location of the kink and how it changes over time depend on expectations. If most individuals expect most firms to be adjusting prices with inflation, and if there are shared views about the rate of inflation, then the price at the kink will move up with inflation: only deviations from expectations (from the norm) give rise to search. Norms can change and change quickly.

The consequences of actions are not only uncertain, but they can also not be costlessly reversed: it will be costly to recruit back a customer who has found another supplier or a good worker who has found another employer. 
Together, risk and adjustment costs imply that there may be an option value in delaying wage decreases and price increases, which gives rise to further rigidities in price-setting in markets.

\section{Uncertainty and the Wage- and Price-Setting Process}

In the price-setting sectors of the economy, differences in the implied risk aversion of firms (resulting in part from differences in net worth) lead to differences across firms in price and wage responses to similar shocks. This increases the possibility that different wages and prices will adjust differently in response to shocks to the economy. This effect is, of course, exacerbated by shocks that have large and differential effects on the net worth of different firms. On the other hand, greater uncertainty may lead to more risk-averse behavior on the part of firms, thus contributing to greater wage and price rigidities (i.e., smaller deviations from perceived norms of adjustments ).

Ex ante, it is not possible to ascertain which effect will predominate. But large shocks, such as those facing East Asia, are more likely to result in a change in norms; and indeed, these markets have been characterized by rapidly falling wages and prices. This is especially the case in Indonesia, where it has been estimated that almost two-thirds of the firms are bankrupt; thus the marginal adverse signaling effect of lowering one's price may, at this juncture, be minimal.

\section{Interactions between Asymmetries in Responses and Imperfections in Information}

The rapid response of asset prices and interest rates to shocks, combined with the imperfections in capital markets that limit the ability of firms to divest themselves of risks, and with the imperfect indexing of debt contracts, has profound implications for the economy's aggregate supply curve. The net worth of firms can change very quickly (Greenwald and Stiglitz, 1993). With risk-averse firms and imperfect risk markets, decreases in net worth lead to large leftward shifts in supply curves. Moreover, the concavity of the supply functions implies that even in a closed economy, where producers of a given product gain from a price rise what purchasers lose, large price changes have macroeconomic effects. Again, East Asia provides an illustration of the phenomenon, as well as a confirmation of the predictions of the theory. There, the increases in interest rates, which were both unexpected and very large, quickly eroded the net worth of the already highly indebted firms. They also reduced net worth through another channel: many firms held substantial wealth in the form of assets like land and stock in other firms, the value of which was adversely affected by the increased interest rates and the associated economic decline. More broadly, to know the impact of a shock on the net worth of any firm requires enormous information, not only about its asset position, but also about the adjustments in prices of the goods it sells and the factors it purchases. A full accounting of net worth requires not only knowing the value of those variables today, but also an estimate of how they will move through time. The larger the disturbance to the economy, the greater the uncertainty.

If all wages and prices were to fall proportionately, matters would be grave enough. But in the previous section, I argued not only that different prices are determined by different adjustment mechanisms, but also that for wageand price-setting firms, patterns of adjustment of their wages and prices will depend on factors idiosyncratic to each firm (such as the change in its net worth and its implicit degree of risk aversion). Therefore prices and wages do not all fall proportionately. And even if there were indexed debt contracts (so that interest rates adjusted to changes in inflation or deflation), different firms would still find their net worth affected differently, and relative prices could deviate significantly from those associated with traditional equilibrium theories, which ignored these effects. Because interest-rate increases have such a large impact on asset values and on the dynamics of adjustment, the large increases in interest rates lead to marked increases in uncertainty.

Increased uncertainty and lower net worth affect the macroeconomy through several channels: through the decreased willingness of risk-averse firms to hire labor, to hold inventories, to produce (except in response to or- 
ders), or to invest. At the same time, agency problems in the economy are likely to increase, one consequence of which is that credit flows get choked off. Aggregate demand and supply are both adversely affected.

Reduced credit flows reinforce all of these effects. Consider trade credit. Firms can be viewed as engaged in both "production", and "financial" activities. Their reduced net worth makes them less willing and able to absorb risk. And the greater uncertainty about their borrowers' position (together with the decline in average net worth of their borrowers) means that lending through trade credit will now be a more risky activity. Reduced lending on the part of banks (a result of tighter supervision, the closure of many banks, and the decreased net worth and increased risk exposure of banks that remain open) reinforces these effects (Greenwald and Stiglitz, 1990b).

As noted earlier, the overall patterns observed in East Asia closely match those predicted by these theories, with four additional observations: First, earlier models focused on closed economies. Because the East Asian economies were open economies, some of the price adjustments (such as the large increases in interest rates) represented redistributions to those outside the economy; there was thus an aggregate-net-worth effect, which reinforced the internal redistributive effect Greenwald and I had earlier emphasized. Second, our earlier models did not focus on the impact of devaluations. As noted, risk-averse firms would typically have cover for their foreignexchange liabilities, so that devaluations would help exporters. Under perfectly flexible wages and prices, nontraded-goods industries would be affected only in the intended way, that is, through a shift of resources from the nontraded to the traded sector. But with relative price rigidities, some nontraded-goods firms may find their input prices rising faster than the prices for the goods which they sell; these firms may thus experience large negative net-worth effects. Third, poor accounting practices (i.e., a lack of transparency) increased the uncertainty: not only were there on average large changes in net worth, but it was also difficult for suppliers of capital to ascertain the magnitude of those changes. Fourth, firms in East Asia were typically highly leveraged, making them even more sensitive to changes in interest rates. The high levels of debt (especially short-term) were far greater than could be explained by an interaction between rational risk-averse borrowers and rational risk-neutral or risk-averse lenders. These deviations from expected behavior can perhaps be interpreted as evidence of moral hazard; lenders, both domestic and foreign, apparently expected to be bailed out. (In cases when the high levels of short-term debt and low levels of transparency are important features of the private-sector landscape, policy should presumably take into account the fact that large increases in interest rates may have particularly large adverse effects.)

Note, however, that it was the large adjustments in some prices that played as important a role in propagating and amplifying the disturbance as did the relative rigidity in other prices. Would still greater flexibility of wages and prices enable the economy to maintain itself at close to full employment? Not obviously: an increased pace of wage and price adjustment, given the contractual rigidities already in place, would have led to even more bankruptcies, greater erosion of net worth, and a more adverse effect on aggregate supply. Nor would indexing have fully resolved these problems, given the large changes in relative prices (e.g., real interest rates and exchange rates).

\section{Concluding Remarks}

This paper has attempted to provide insights into the three key macroeconomic questions: Why do wages in the labor market not adjust to clear the labor market? How can we explain the magnitude of the changes in the demand curve for labor, which seem to necessitate such large changes in real wages to equilibrate that market? And why do adjustments in person-hours take the form they do, with a disproportionate share of the adjustment in downturns occurring in the form of employment? In addressing these questions, I have unified the two alternative strands in new-Keynesian economics, one focusing on rigidities, the other on the 
adverse consequences of downward movements in prices. I have argued that asymmetries of adjustment and imperfections of information are key; the asymmetries are particularly pronounced between those markets (like assets) where auction processes prevail and those in which firms engage in price-setting. It is relative rigidities, not absolute ones, that matter. In the case of price-setting firms, a dynamic portfolio theory of adjustment that (i) incorporates both prices and quantities, (ii) takes into account nonlinearities, fixed costs, and irreversibilities, and (iii) incorporates signaling impacts of changes and option values can explain not only slow speeds of adjustment, but even rigidities. (Specifically, it explains rigidities of the sort where changes in the environment lead to no change in firm behavior: for example, because of kinks in the perceived demand curves facing firms.) I have argued that it is not just the price of goods and labor relative to money that matters in determining macroeconomic fluctuations; disturbances ("deviations from full equilibrium") of other relative prices may matter even more.

The theory has, at the same time, strong policy implications. It agrees in some respects with traditional Keynesian prescriptions and differs in others, but most importantly it calls attention to aspects of policy that are too often ignored and that have played out with a vengeance in East Asia. Falling wages and prices (increased price flexibility) in the presence of incomplete contracting may have negative impacts that far outweigh positive real-balance effects. Impacts on asset values and cash flows of different policies have first-order effects. Monetary policy has impacts not only through channels traditionally emphasized, including credit availability, but also through changes in asset values and cash constraints facing firms. Aggregate demand and aggregate supply are intimately intertwined, so that demand shifts that reduce the net worth of firms have significant impacts on aggregate supply in subsequent periods. The fact that these effects are persistent and hard to reverse in turn has strong implications for the design of the appropriate macroeconomic policies. While there is always some uncertainty about the future position of the economy and the consequences of alternative policies, risks are asymmetric. This is perhaps one of the central lessons to emerge from the crisis in East Asia.

\section{REFERENCES}

Edlin, Aaron S. and Stiglitz, Joseph E. "'Discouraging Rivals: Managerial Rent-Seeking and Economic Inefficiencies." American Economic Review, December 1995, 85(5), pp. 1301-12.

Greenwald, Bruce C. “'International Adjustment in the Face of Imperfect Capital Markets." Unpublished manuscript presented at the 1998 Annual Bank Conference for Development Economics, World Bank, Washington, DC, 1998.

Greenwald, Bruce C. and Stiglitz, Joseph E. " Examining Alternative Macroeconomic Theories." Brookings Papers on Economic Activity, 1988, (1), pp. 207-60.

"'Toward a Theory of Rigidities." American Economic Review, May 1989 (Papers and Proceedings), 79(2), pp. 364-69.

"Asymmetric Information and the New Theory of the Firm: Financial Constraints and Risk Behavior." American Economic Review, May 1990a (Papers and Proceedings), $80(2)$, pp. 160-65.

"Macroeconomic Models with Equity and Credit Rationing,"' in R. B. Hubbard, ed., Asymmetric information, corporate finance, and investment. Chicago: University of Chicago Press, 1990b, pp. $15-42$.

. "Financial Market Imperfections and Business Cycles." Quarterly Journal of Economics, February 1993, 108(1), pp. 77-114.

"Labor Market Adjustments and the Persistence of Unemployment." American Economic Review, May 1995 (Papers and Proceedings), 85(2), pp. 219-25.

Stiglitz, Joseph E. "Competition and the Number of Firms in a Market: Are Duopolies More Competitive Than Atomistic Markets?' Journal of Political Economy, October 1987, 95(5), pp. 1041-61.

World Bank. Global economic prospects and the developing countries 1998/99: Beyond financial crisis. Washington, DC: World Bank, 1998. 
Copyright of American Economic Review is the property of American Economic Association. The copyright in an individual article may be maintained by the author in certain cases. Content may not be copied or emailed to multiple sites or posted to a listserv without the copyright holder's express written permission. However, users may print, download, or email articles for individual use. 